\title{
Marie Brockmann-Jerosch and her influence on Alpine phylogeography
}

\author{
Rolf Holderegger • Conny Thiel-Egenter • \\ Christian Parisod
}

Received: 31 October 2009/Revised: 26 February 2010/Accepted: 11 March 2010/Published online: 26 January 2011

(C) Swiss Botanical Society 2011

\begin{abstract}
At the beginning of the twentieth century, Marie Brockmann-Jerosch wrote, partly in collaboration with her husband Heinrich Brockmann-Jerosch, three influential overview articles on the origin and history of the Swiss alpine flora. Of special interest to her were the types and locations of Pleistocene glacial refugia of alpine plants. She summarised that there had been glacial refugia in the southern and northern peripheral European Alps and also supported glacial survival of high-alpine specialist plants in central Alpine nunatak regions within glaciated areas of the Alps. In contrast, Marie Brockmann-Jerosch dismissed the occurrence of glacial relicts in the lowlands and foothills north of the Alps: she rather saw the conspicuous stations of alpine plants in the lowlands as the result of post-glacial long-distance dispersal of seed out of the Alps. In this article, we first give a brief description of Marie BrockmannJerosch's life and then show that modern phylogeographic research has largely proven her views of the glacial history of
\end{abstract}

R. Holderegger $(\square)$

WSL Swiss Federal Research Institute,

Zürcherstrasse 111, 8903 Birmensdorf, Switzerland

e-mail: rolf.holderegger@wsl.ch

R. Holderegger

Department of Environmental Sciences, ETH Zürich,

Universitätsstrasse 16, 8092 Zürich, Switzerland

C. Thiel-Egenter

FORNAT AG Forschung für Naturschutz und Naturnutzung,

Universitätstrasse 47, 8006 Zürich, Switzerland

C. Parisod

National Centre for Biosystematics and Natural History

Museum, University of Oslo, PO Box 1172 ,

Blindern 0318 Oslo, Norway the alpine flora and that her writings are still intellectually stimulating and worthwhile reading.

Keywords Alpine plants - Biogeography -

Central Alpine glacial refugia - Glacial relicts .

History of botany $\cdot$ Peripheral glacial refugia

\section{Introduction}

Phylogeographic studies deal with the historical biogeography of organisms by investigating the genetic signal of past events such as dispersal, migration, survival or range expansion and contraction. In brief, the genetic relatedness of contemporary individuals and populations reflects their past (Avise 2000). In the European Alps, the phylogeography of alpine plant species has received much interest during the past 10 years and, especially so, their glacial history. Where did alpine plant species survive glaciation? Which were the (re)-immigration pathways out of these refugia along which alpine plants recolonised the Alps when the glaciers finally retreated at the end of the last glaciation? One hundred years ago, Marie Brockmann-Jerosch asked similar questions, and three of her articles still influence the field of modern Alpine phylogeography (Jerosch 1903; BrockmannJerosch 1908; Brockmann-Jerosch and Brockmann-Jerosch 1926). In these articles, she reviewed and summarised the knowledge on the glacial history of the Swiss alpine flora available from the published literature at that time. These early critical overviews set up the biogeographic foundations against which present-day molecular-genetic research tests its hypotheses on the phylogeography and glacial history of alpine plants.

In the present article, we first give a short account of Marie Brockmann-Jerosch's life and then review how 
modern phylogeography of alpine plant species confirmed or falsified the main conclusions of Marie BrockmannJerosch on where alpine plant species survived the ice ages (i.e. glacial refugia). In doing so, we focus on Switzerland and on her later work (i.e. Brockmann-Jerosch and BrockmannJerosch 1926; if not otherwise stated, page citations refer to this latter article, and English translations are by the authors).

\section{The life of Marie Brockmann-Jerosch (1877-1952)}

Marie Jerosch (Fig. 1) from Königsberg (formerly East Prussia, now Russia) came to Zürich in order to study biology at the University of Zürich. After a botanical field trip to the Rigi, an often visited mountain peak of the northern peripheral Alps in Switzerland, led by Carl Schröter, she enthusiastically changed to the ETH Zürich in order to study botany and geology with Carl Schröter (professor in botany) and Albert Heim (professor in geology). Both professors were renowned for encouraging women to study at ETH Zürich in those early days when the first female students entered Swiss universities (Müller 2005).

In 1903, Marie Jerosch published, in German, her first book entitled 'History and origin of the Swiss alpine flora: an overview on the present state of the question', which focused on the evolution of the alpine flora (Jerosch 1903). Although often assumed to be her PhD-thesis, this book was, in fact, her diploma thesis. "The object of this book is not to offer a new theory regarding the origin of the flora of the Swiss Alps, but to bring together the views, which have been put

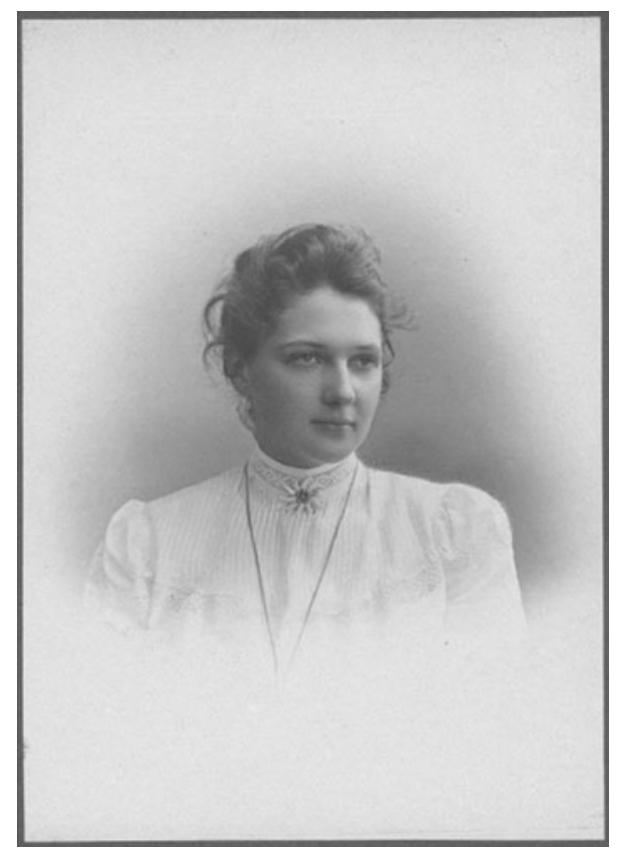

Fig. 1 Marie Jerosch (around 1901; source: ETH Bibliothek Zürich, Bildarchiv) forward by leading botanists, partly for reference, partly with the object of comparing them and criticising them so far as it is possible to criticise the evidence of experts" stated a review of Marie Jerosch's book published in the prestigious British journal 'Nature' (Anonymous 1904: 340). Her book had a major influence on Alpine biogeography, at least in German-speaking countries. Marie Jerosch's PhD-thesis, under the supervision of Albert Heim, dealt with the geology of the Säntis mountain massive in Eastern Switzerland (Jerosch 1904). In 1905, she married the botanist Heinrich Brockmann. Some years later, Carl Schröter asked her to write a rather brief chapter on 'The history of the alpine flora' (Brockmann-Jerosch 1908) for the first edition of his epochal textbook 'The plant life of the Alps' (Schröter 1908; Rübel 1953). Marie Brockmann-Jerosch modestly stated in the preface that her chapter simply was a shortened extract of her book from 1903, with only some relevant recently published articles added.

For the second edition of Carl Schröter's textbook on alpine plant life (Schröter 1926), Marie and Heinrich Brockmann-Jerosch wrote together a new chapter of more than 100 pages on 'The history of the Swiss alpine flora' (Brockmann-Jerosch and Brockmann-Jerosch 1926). The content of the chapter had much changed as compared with the first edition. Although generally summarising the existing knowledge and critically reviewing corresponding points of view on themes such as the geology of the Alps, the fossil record, the distribution of alpine plants, the evolutionary origin of the alpine flora or contemporary changes in its composition, particular attention was paid to the glacial and postglacial history of alpine plants. In fact, a major part of the chapter dealt with this latter subject. The original contributions of Marie and Heinrich Brockmann-Jerosch to the chapter cannot be separated from hindsight. Rübel (1953) simply stated that, in the new chapter, the ideas of Marie Brockmann-Jerosch were interwoven with those of her husband. Nevertheless, we believe that Marie BrockmannJerosch contributed the major thoughts and ideas, as she worked on the theme of alpine plant biogeography ever since her diploma thesis. It is mainly this chapter in the second edition of Schröter's textbook from 1926 on which bases the long-lasting influence of Marie Brockmann-Jerosch on the biogeography of alpine plants.

After the death of her husband in 1939, Marie BrockmannJerosch worked as curator and teacher at the Geobotanical Institute in Zürich. She died in 1952 (Rübel 1953).

\section{The theoretical basis of Marie Brockmann-Jerosch's work}

Well educated in botany and geology, Marie BrockmannJerosch based her considerations on the glacial history of 
the alpine flora on geological and botanical (i.e. biogeographic) evidence. She stressed, together with her husband, that one should not mix evidence based on geology with evidence based on floristics in order to avoid circular reasoning. In the absence of fossils (p. 1117), the investigation of the glacial history of alpine plants based on three types of evidence. First, Marie Brockmann-Jerosch considered the geological evidence on the extent of ice sheets and glaciers, and thus on potentially ice-free areas. Second, she took into account the distribution range of alpine plants, especially of endemics, as well as centres of alpine species richness. Third, she referred to a rather vague 'genetic element'. She used the term 'genetic' in the sense of descent and noted that the investigation of the relationships of individuals from different locations within a species' distribution range should allow determining which populations descended from which other original populations. Without any appropriate genetic methods at her hands, she thought about studying morphological differences among individuals or investigating types, forms or variants within species (p. 1150). This approach has not been used in a substantial way later on. However, and in modern jargon, Marie Brockmann-Jerosch wanted to determine the genetic and evolutionary relationships of populations of alpine plants in order to identify the locations of glacial refugia. This is exactly the approach of modern Alpine phylogeography, which uses molecular-genetic tools to determine the relatedness of individuals and populations to reveal the glacial history of alpine plants (Schönswetter et al. 2005). Marie Brockmann-Jerosch can thus be seen as an early proponent of Alpine phylogeography.

\section{Glacial survival within glaciated regions: southern peripheral refugia}

Based on the published literature and the views expressed by prominent botanists of the time (e.g. Briquet 1906, 1908), Brockmann-Jerosch and Brockmann-Jerosch (1926) discussed four major types of glacial refugia for alpine plants: peripheral refugia in the southern Alps, peripheral refugia in the northern Alps, central Alpine refugia and glacial survival in the lowlands and foothills north of the Alps (i.e. glacial relicts; see below).

Based on the distribution of species and, in particular of endemic species, the southern peripheral Alps all along the Alpine arch should have served as glacial refugia. This claim was, of course, also supported by the lower degree of glaciation of the southern peripheral Alps as compared with the northern peripheral or central Alps. Brockmann-Jerosch and Brockmann-Jerosch (1926) claimed that "after the ice ages, the central core [of the Alps] has been colonised out of the peripheral refugia in a centripetal way" (p. 1187) and that a major migration pathway followed the southern periphery of the Alps (p. 1182; Chodat and Pampanini 1902). From this major migration pathway, alpine plant species did then cross alpine passes (e.g. in the Valais or the Engadine) and re-colonised the central Alps in this way.

Modern phylogeographic research indeed showed that the southern peripheral Alps served as refugia for alpine species (Schönswetter et al. 2005). This holds especially true for species of siliceous bedrock; siliceous bedrock being the dominant bedrock in the southern peripheral Alps. Examples of species showing (several) glacial refugia along the southern Alps are Androsace alpina (Schönswetter et al. 2003a), Eritrichium nanum (Stehlik et al. 2002a), Phyteuma globulariifolium (Schönswetter et al. 2002) or Ranunculus glacialis (Schönswetter et al. 2003b). Although these studies showed that the eastern peripheral Alps also harboured important refugial areas during the ice ages (Schönswetter et al. 2005), Marie Brockmann-Jerosch's conclusion of major glacial refugia in the southern peripheral Alps has largely been verified by modern phylogeography. Similarly, phylogeographic studies showed that Alpine passes served as re-immigration pathways for alpine plant species. Parisod (2008) discussed evidence for the post-glacial migration of Biscutella laevigata over alpine passes (e.g. Simplon, Fenêtre Durand or Theodul passes).

\section{Glacial survival within glaciated regions: northern peripheral refugia}

In contrast to the southern peripheral Alps, the northern peripheral Alps are mainly composed of calcareous bedrock. Brockmann-Jerosch and Brockmann-Jerosch (p. 11881189) argued that the northern peripheral chains of the Alps might have served as glacial refugia for plant species of calcareous bedrock. However, they also stated that there was hardly any evidence for this in the published literature. Surprisingly, they named the Napf region in the Canton of Bern as an example of such a northern peripheral refugium. The Napf is situated in the northern foothills of the Swiss Alps (Lüdi 1928), which would nowadays hardly be seen as a northern peripheral refugium (see below). One would rather assign mountains such as Vanil Noir, Brienzer Rothorn, Pilatus or Säntis to this category of glacial refugia (Stehlik 2000).

In contrast to southern peripheral refugia, only few studies investigated northern glacial refugia (Schönswetter et al. 2005). Stehlik et al. (2002b) found some genetic indication of glacial survival of Erinus alpinus in northern peripheral areas in Switzerland. Although the majority of the Swiss populations of E. alpinus clearly originated from re-immigration out of the French Southern Alps, some areas in Switzerland, namely the mountains Rigi and Säntis, had a deviating genetic composition pointing to local glacial 
refugia in the northern peripheral Alps. Similarly, Stehlik (2002) found local glacial refugia for Rumex nivalis in the areas of Lake Brienz and Säntis-Churfirsten, both in Switzerland, or Oberstdorf in Germany. In addition, Parisod and Besnard (2007) located glacial refugia of B. laevigata in the northern peripheral Alps between Lake Geneva and Lake Brienz (Parisod 2008). Although not directly aimed at detecting glacial refugia, a large survey of the genetic structure of 27 alpine plants reported results that also support northern peripheral refugia (Alvarez et al. 2009). Albeit additional phylogeographic investigations are required, one can already confirm the existence of peripheral refugia in the northern Alps.

\section{Glacial survival within glaciated regions: central Alpine refugia}

In the early twentieth century, botanists strongly debated the issue of whether alpine plants were able to survive the ice ages on ice-free mountain peaks and slopes within the heavily glaciated central Alps (p. 1204). While many botanists denied this type of glacial refugia, others tended to accept such nunatak survival, principally because some heavily glaciated areas show high floristic richness both with respect to species and endemics (p. 1180). Marie Brockmann-Jerosch was generally in favour of nunatak survival in the central Alps (p. 1115) and, according to the literature, named corresponding areas in Switzerland such as the Penninic Alps in the Valais, especially the Zermatt and Simplon regions, or the mountains of the Engadine and the Avers valley (p. 1201). However, Brockmann-Jerosch and Brockmann-Jerosch (1926) clearly stated that only highalpine specialists and not just any alpine plant species had been able to survive in nunatak regions of the central Alps (p. 1201); a restriction that has often been neglected in biogeographic research on alpine plants during the twentieth century.

Swiss botanists played a leading role in testing nunatak survival of alpine plants in the central Alps during recent years. Convincing genetic evidence for central Alpine glacial refugia was, however, only obtained for a handful of species. Stehlik et al. (2002a) found that the high-alpine cushion plant $E$. nanum had central glacial refugia in the Zermatt and Simplon regions as well as in the Upper Engadine. A central glacial refugium in the Zermatt-Simplon region was also detected for Senecio halleri by Bettin et al. (2007), while Parisod and Besnard (2007) located a central glacial refugium of $B$. laevigata near the Zermatt region. In addition, Thiel-Egenter et al. (2008) found indirect evidence (based on genetic diversity) for nunatak survival for those alpine plants that are restricted to the highest vegetation belts. However, for several other alpine plant species, phylogeographic studies did not find any evidence for glacial survival on nunataks (e.g. Holderegger et al. 2002).

Despite accumulating phylogeographic evidence for glacial survival in nutatak regions of the central Alps (Schönswetter et al. 2005), the existence of such central glacial refugia is still, as it has been 100 years ago, a matter of debate, with many scientists doubting their relevance for glacial survival (Hewitt 2004): the question of central Alpine refugia is thus not yet settled.

\section{Glacial survival outside of glaciated regions: glacial relicts}

At the beginning of the twentieth century, the scientific debate on the topic of glacial relicts ran high (Nägeli 1903; Hegi 1904; Lüdi 1928). Glacial relicts are mountain or alpine plants that have stations in the European lowlands or in the foothills of the Alps (e.g. the Napf region, the Tössbergland or the Üetliberg near Zürich; Spillmann and Holderegger 2008), i.e. outside of the species' main distribution ranges in the Alps. These stations were seen as relict small populations that had survived in spatially restricted locations since the retreat of the glaciers. Mountain species growing on erratic rocks played a particularly important role in these arguments, and glacial relicts were seen as "living witnesses" of the ice ages (p. 1157).

Brockmann-Jerosch and Brockmann-Jerosch (1926) devoted a whole chapter of 28 pages to the subject of glacial relicts, which reflects the importance of the topic at that time. They sceptically wrote: "The more one thinks about the problem of glacial relicts - and this holds partly true for other types of relics - the more the climatic character of this problem changes into an ecological character in the widest sense of the term. Suitable habitat patches and, at the same time, the lack of competition by the flora of forests or fertilised meadows is the necessary prerequisite for the occurrence of glacial relicts and, by the way, also of their apparent antipodes, namely the xeric relicts. [...] The problem of glacial relicts would not be so multi-faceted and would never have become so prominent, if two different lines of reasoning would not have been confounded, namely, first, that the colonies of glacial relicts live at those locations that they already occupied under glacial conditions [... and], second, that the glacial relicts are the remains of that flora that was generally wide-spread during the ice ages and that glacial relicts therefore give testimony of the climatic conditions at that time" (p. 1177).

In fact, Brockmann-Jerosch and Brockmann-Jerosch (1926) had a clear-cut view on glacial relicts, which they proclaimed in a stringent reasoning, sometimes violently attacking other botanists (especially Gustav Hegi; e.g. p. 1160). From the fossil record, they concluded that there 
was no arctic-alpine flora in the lowlands north of the Alps during the ice ages (p. 1155) and explained the stations of alpine species in the lowlands and foothills of the Alps as the result of contemporary ecological conditions and long-distance dispersal of seed out of the Alps ("saltational dispersal"; p. 1155). Indeed, Marie and Heinrich Brockmann-Jerosch strongly believed in the ability of plants for long-distance seed dispersal and, hence, the possibility that plants can colonise even distant places. This view has now become a widely accepted fact (Nathan 2006). BrockmannJerosch and Brockmann-Jerosch (1926) scrupulously reported on (often anecdotal) findings that supported their conclusion that the locations of glacial relicts mainly, if not generally, resulted from post-glacial or even contemporary long-distance seed dispersal.

The article of Brockmann-Jerosch and BrockmannJerosch (1926) settled the matter of glacial relicts in Switzerland. Later on, the topic vanished from the research agenda (Spillmann and Holderegger 2008), although the term is still used in various, often un-reflected ways in contemporary floristic studies. However, and early on, Manton (1932) provided some compelling evidence favouring the glacial relict hypothesis. She showed that the tetraploid populations of B. laevigata found in the Alps were derived from remnant diploid populations occurring in the lowlands, notably in Germany (Manton 1932). This scenario has been recently confirmed by phylogeographic work (Tremetsberger et al. 2002; Parisod and Besnard 2007). In accordance, Reisch et al. (2003) found some evidence in favour of the glacial relict hypothesis for lowland stations of Saxifraga paniculata in Germany, but no corresponding evidence was detected for Sesleria albicans in Germany (Reisch et al. 2002) or Saxifraga aizoides in the Swiss Canton of Zürich (Lutz et al. 2000). For the especially scattered and small populations of Asplenium septentrionale mainly occurring on erratic rocks in the Swiss lowlands and being one of the historically most prominent examples of a glacial relict species (p. 1165), Holderegger and Schneller (1994) showed that the present lowland stations are rather the result of long-distance dispersal of spores than being glacial remnants.

Phylogeographic evidence for glacial refugia of alpine plants in the lowlands (Holderegger and Thiel-Egenter 2009) is still equivocal, and additional work is needed to finally prove their existence and relevance (Provan and Bennett 2008).

\section{Conclusions}

The major views and conclusions of Marie BrockmannJerosch were largely proven by modern phylogeography. Especially, her opinion about the types and locations of glacial refugia of alpine plants proved right (Holderegger and Thiel-Egenter 2009). She also clearly saw that the local flora is the result of the interaction between the local environment (soil, climate) and history (survival, extinction and migration; Alvarez et al. 2009).

Although many earlier authors made substantial contributions to the glacial history of alpine plants (e.g. Christ 1879; Chodat and Pampanini 1902; Briquet 1906, 1908), it was Marie Brockmann-Jerosch's own virtue to critically summarise the then existing literature and the then held views on the glacial history of the alpine flora (both in her own articles as well as in the article published with her husband). In doing so, she sometimes harshly criticised common scientific belief. However, it is her conceptual approach and her analytical attitude, which make her articles still a worthwhile reading. At the beginning of the twentyfirst century, Marie Brockmann-Jerosch's writings are intellectually as stimulating and relevant as they had been 100 years ago when they were first published.

Acknowledgments We thank Michèle Büttner and two anonymous referees for helpful comments on the manuscript.

\section{References}

Alvarez N, Thiel-Egenter C, Tribsch A, Holderegger R, Manel S, Schönswetter P, Taberlet P, Brodbeck S, Gaudeul M, Gielly L, Küpfer P, Mansion G, Negrini R, Paun O, Pellecchia M, Rioux D, Schüpfer F, Van Loo M, Winkler M, Gugerli F, INTRABIODIV Consortium (2009) History or ecology? Substrate type as a major driver of spatial genetic structure in alpine plants. Ecol Lett 12:632-640

Anonymous (1904) The flora of the Swiss Alps (book review). Nature 69:340

Avise JC (2000) Phylogeography. The history and formation of species. Harvard University Press, Cambridge

Bettin O, Cornejo C, Edwards PJ, Holderegger R (2007) Phylogeography of the high alpine plant Senecio halleri (Asteraceae) in the European Alps: in situ glacial survival with postglacial stepwise dispersal into peripheral areas. Mol Ecol 16:2517-2524

Briquet J (1906) Le développement des flores dans les alpes occidentales avec aperçu sur les alpes en général. In: Wettstein R, Wiesner J, Zahlbruckner A (eds) Wissenschaftliche Ergebnisse des Internationalen Botanischen Kongresses Wien 1905. Fischer, Jena, pp 130-173

Briquet J (1908) Les réimmigrations postglaciaires des flores en Suisse. Verh Schweizer Naturforsch Ges 90(I):112-133

Brockmann-Jerosch M (1908) Die Geschichte der Schweizerischen Alpenflora. In: Schröter C (ed) Das Pflanzenleben der Alpen, 1st edn. Raustein, Zürich, pp 743-777

Brockmann-Jerosch H, Brockmann-Jerosch MC (1926) Die Geschichte der Schweizerischen Alpenflora. In: Schröter C (ed) Das Pflanzenleben der Alpen, 2nd edn. Raustein, Zürich, pp 1110-1215

Chodat R, Pampanini R (1902) Sur la distribution des plantes dans les alpes austro-orientales et plus particulièrement d'un choix de plantes des alpes cadoriques et vénitiennes. Le Globe 41:1-70

Christ H (1879) Das Pflanzenleben der Schweiz. Schulthess, Zürich

Hegi G (1904) Die Alpenpflanzen des Zürcher Oberlandes. Verh Schweizer Naturforsch Ges 87:230-243 
Hewitt GM (2004) Genetic consequences of climatic oscillations in the Quaternary. Phil Trans R Soc Lond B 359:183-195

Holderegger R, Schneller JJ (1994) Are small isolated populations of Asplenium septentrionale variable? Biol J Linn Soc 51:377-385

Holderegger R, Thiel-Egenter C (2009) A discussion of different types of glacial refugia used in mountain biogeography and phylogeography. J Biogeogr 36:476-480

Holderegger R, Stehlik I, Abbott RJ (2002) Molecular analysis of the Pleistocene history of Saxifraga oppositifolia in the Alps. Mol Ecol 11:1409-1418

Jerosch MC (1903) Geschichte und Herkunft der Schweizerischen Alpenflora. Eine Übersicht über den gegenwärtigen Stand der Frage. Engelmann, Leipzig

Jerosch MC (1904) Die Querstörungen im mittleren Teil des Säntisgebirges, PhD-thesis. University of Zürich, Zürich

Lüdi W (1928) Die Alpenpflanzenkolonien des Napfgebietes und die Geschichte ihrer Entstehung. Mitt Naturforsch Ges Bern 1927:195-265

Lutz E, Holderegger R, Schneller JJ (2000) Understanding population history for conservation purposes: population genetics of Saxifraga aizoides (Saxifragaceae) in the lowlands and lower mountains north of the Alps. Am J Bot 87:583-590

Manton I (1932) Introduction to the general cytology of the Crucifera. Ann Bot 46:509-556

Müller VE (2005) Erste Schritte am Poly: Die Pionierinnen. Bull ETH Zürich 297:7-11

Nägeli O (1903) Zur Herkunft der Alpenpflanzen des Zürcher Oberlandes. Ber Zürcher Bot Ges 8:63-69

Nathan R (2006) Long-distance dispersal of plants. Science 313:786-788

Parisod C (2008) Postglacial recolonisation of plants in the western Alps of Switzerland. Bot Helv 118:1-12

Parisod C, Besnard G (2007) Glacial in situ survival in the Western Alps and polytopic autopolyploidy in Biscutella laevigata L. (Brassicaceae). Mol Ecol 16:2755-2767

Provan J, Bennett KD (2008) Phylogeographic insights into cryptic glacial refugia. Trends Ecol Evol 23:564-571

Reisch C, Poschlod P, Wingender R (2002) Genetic variation of Sesleria albicans Kit. ex Schultes (Poaceae): lack of evidence for glacial relict endemism in central Europe. Plant Biol 4:711-719

Reisch C, Poschlod P, Wingender R (2003) Genetic variation of Saxifraga paniculata Mill. (Saxifragaceae): molecular evidence for glacial relict endemism in central Europe. Biol J Linn Soc 80:11-21
Rübel E (1953) Marie Brockmann-Jerosch. Ber Geobot Inst ETH Zürich 1952:12-14

Schönswetter P, Tribsch A, Barfuss M, Niklfeld H (2002) Several Pleistocene refugia detected in the high alpine plant Phyteuma globulariiifolium Sternb. \& Hoppe (Campanulaceae) in the European Alps. Mol Ecol 11:2637-2647

Schönswetter P, Tribsch A, Niklfeld H (2003a) Phylogeography of the alpine cushion-plant Androcase alpina (Primulaceae) in the European Alps. Plant Biol 5:623-630

Schönswetter P, Paun O, Tribsch A, Niklfeld H (2003b) Out of the Alps, colonisation of the Arctic by East Alpine populations of Ranunculus glacialis (Ranunculaceae). Mol Ecol 12:3373-3381

Schönswetter P, Stehlik I, Holderegger R, Tribsch A (2005) Molecular evidence for glacial refugia of mountain plants in the European Alps. Mol Ecol 14:3547-3555

Schröter C (1908) Das Pflanzenleben der Alpen, 1st edn. Raustein, Zürich

Schröter C (1926) Das Pflanzenleben der Alpen, 2nd edn. Raustein, Zürich

Spillmann JH, Holderegger R (2008) Die Alpenpflanzen des Tössberglandes. Einhundert Jahre nach Gustav Hegi. Haupt, Bern

Stehlik I (2000) Nunataks and peripheral refugia for alpine plants during Quaternary glaciation in the middle part of the Alps. Bot Helv 110:25-30

Stehlik I (2002) Glacial history of the alpine herb Rumex nivalis (Polygonaceae): a comparison of common phylogeographic methods with nested clade analysis. Am J Bot 89:2007-2016

Stehlik I, Blattner F, Holderegger R, Bachmann K (2002a) Nunatak survival of the high alpine plant Eritrichium nanum (L.) Gaudin in the central Alps during the ice ages. Mol Ecol 11:2027-2036

Stehlik I, Schneller JJ, Bachmann K (2002b) Immigration and in situ glacial survival of the low-alpine Erinus alpinus (Scruphulariaceae). Biol J Linn Soc 77:87-103

Thiel-Egenter C, Gugerli F, Alvarez N, Brodbeck S, Cieślak E, Colli L, Englisch T, Gaudeul M, Gielly L, Korbecka G, Negrini R, Paun O, Pellecchia M, Rioux D, Ronikier M, Schönswetter P, Schüpfer F, Taberlet $\mathrm{P}$, Tribsch A, Van Loo M, Winkler M, Holderegger R, INTRABIODIV Consortium (2008) Effects of species traits on the genetic diversity of high-mountain plants: a multi-species study across the Alps and the Carpathians. Global Ecol Biogeogr 18:78-87

Tremetsberger K, König C, Samuel R, Pinsker W, Stuessy TF (2002) Infraspecific genetic variation in Biscutella laevigata (Brassicaceae): new focus on Irene Manton's hypothesis. Plant Syst Evol 233:163-181 